\title{
Publicística novohispana de 1821: ¿independencia o sujeción a España?
}

\author{
Manuel Ferrer Muñoz \\ Instituto de Investigaciones Jurídicas, \\ UNAM. México, D. F.
}

La proclamación del Plan de Iguala, en febrero de 1821, confirió unas características particulares a la producción publicística de la Nueva España durante los meses que transcurrieron hasta la definitiva ruptura con España. Se entiende que, en esas circunstancias incendiarias, las tomas de postura a favor o en contra de la independencia aparecieran revestidas de apasionamiento, y que la coyuntura política del momento - el irregular relevo de Ruiz de Apodaca por Novella, y la llegada de O'Donojú- condicionara muchos de aquellos discursos. Valía la pena tratar de un modo sistemático esa folletería, y desentrañar las razones invocadas desde uno y otro bando para legitimar posiciones. $Y$ ése es el propósito de este artículo, que se sustenta en la consulta de un vasto material hemerográfico.

La proclamación de independencia facilitó la difusión y traducción de obras de autores ilustrados y revolucionarios, franceses e ingleses, de sus comentaristas, y de escritos divulgadores del constitucionalismo norteamericano que antes resultaba muy difícil adquirir en las librerías. ${ }^{1}$ Entre los lectores de estos impresos no encontramos tan sólo a los legisladores de 1823-1824: hubo además un sector ilustrado de la población que se había familiarizado con esa literatura política y que se esforzó por propalarla a través de folletos o de publicaciones periódicas. ${ }^{2}$

No parece prudente, sin embargo, imaginar que el entusiasmo por esas ideas hubiera prendido conscientemente en estratos amplios de la sociedad, ni que la propuesta emancipadora revistiera un carácter popular, al menos en el sentido de que la gente común poseyera una percepción clara del hecho que aclamaban, incluso con frenesí, en calles y plazas, en tertulias y cafés. ${ }^{3}$

1 Por supuesto, existían otros conductos para el acceso a esas obras, muchas de las cuales se introducían y circulaban en la Nueva España de modo fraudulento. Pérez-Marchand ha estudiado algunos de los mecanismos utilizados para burlar el control ejercido por las autoridades. Pérez-Marchand, Monelisa Lina: Dos Etapas Ideológicas del Siglo XVIII en México a través de los papeles de la Inquisición, México, 1945, págs. 92-98.

2 Sierra Brabatta, Carlos J.: La Constitución Federal de 1824, México, 1983, págs. 45-51.

3 Ocampo, Javier: Las ideas de un día. El pueblo mexicano ante la consumación de su Independencia, México, 1969, págs. 53-58. 
La acusada distinción entre una minoría ilustrada y una mayoría iletrada ha conducido a algunos investigadores a formular la tesis de que los movimientos de independencia hispanoamericanos —incluido el de México- no fueron levantamientos genuinamente populares, sino "revoluciones políticas organizadas y propulsadas por las clases medias cultas y algunos grupos de las altas". Por eso, la comprensión teórica de las razones que impulsaron la lucha emancipadora puede basarse legítimamente en el examen de la literatura panfletaria que produjeron los grupos sociales más altos. ${ }^{4}$

Se precisa una última advertencia antes de entrar definitivamente en materia, y es que la folletería de 1821 es hija de las circunstancias incendiarias de ese año: publicada cuando la ruptura total con España era inminente o había sido ya realizada, fue concebida para lograr que la opinión pública cristalizara en favor de la independencia. Y ese carácter instrumental implicaba, necesariamente, una fuerte dosis de "exageración deliberada de los vicios y de la maldad españoles", en abierto contraste con la idealización de América que, a los ojos de los panfletistas, encerraba una potencialidad sin límites. ${ }^{5}$

A pesar del escepticismo cada vez más difundido en 1821, el retorno al orden constitucional propugnado por los órganos escritos de expresión estuvo marcado en sus orígenes por sinceros deseos de conciliación, tales como los que había manifestado una Proclama de un americano á los insurjentes, impresa en México en el mes de agosto de 1820, cuyo autor - El Americano Liberal, J.V. - participaba de la presunta fe de Fernando en los instrumentos constitucionales como vehículo de pacificación, y destacaba la circunstancia de que en los medios públicos de la Península se prefería el término de "disidentes" para designar a los americanos descontentos, hasta entonces llamados "insurgentes".

Si El Americano Liberal empleaba esta denominación, lo hacía porque ese nombre era "el mas común y conocido hasta por ellos mismos, pero de ninguna manera por injuriar ni envilecer con el á mis paisanos". Las apatías y los temores que observaba entre sus conciudadanos a los pocos meses de que hubiera entrado en vigor la Constitución le movían a excitar su patriotismo y a fiarlo todo en la integridad del rey: "el ha jurado poco ha en manos del soberano Congreso de las cortes, constituirse el defensor ace-

4 Bachman, John E.: "Los panfletos de la independencia", en Historia Mexicana, vol. XX, núm. 80, México, abril-junio de 1971, págs. 522-538 (págs. 522-523).

5 Ibídem, págs. 530-531. 
rrimo de nuestra libertad, y nosotros guardarla y sostenerla para hacer este Código inmortal". ${ }^{6}$

También El Mejicano Independiente parecía compartir el aprecio hacia la persona del rey español, y rechazaba la imputación de que los propugnadores de la emancipación hubieran negado la obediencia a Fernando VII: "pedimos solamente que se establezca y radique entre nosotros para estrechar más y más los vínculos de nuestra sumisión, queremos gozar de su real presencia para que la interposicion de los Mares no debilite los influjos benéficos de su augusto Trono".

Sin embargo, la perpetuación de los antagonismos entre europeos y americanos, aun después de que recuperara vigor la Constitución en Nueva España, indujo a muchos panegiristas del nuevo régimen a clamar contra ese "espíritu de partido" que obstruía el aquietamiento. En busca de elementos de coincidencia entre unos y otros, se destacaba la común hostilidad al "gobierno arbitrario y opresor que por nuestra desgracia ha oprimido á unos y otros tantos años". Desde ese prisma, la insurrección de 1810 no había tenido por móvil el odio al europeo sino el "erroneo sistema de gobierno", y si los disidentes

"creyeron justo y necesario declararle la guerra al europeo, fué no principalmente ni por destruirlo inspirados del odio, sino accesoriamente y en cuanto ellos juzgaron que vosotros os habíais de oponer con todos los posibles esfuerzos á sostener las miras de un tirano gobierno que pretendian destruir". ${ }^{8}$

Ni la llegada de nuevos tiempos ni los cambios políticos operados desde 1820 tuvieron su continuidad en América: no sólo seguía predominando la incomprensión por parte del Gobierno peninsular, sino que una pequeña minoría opuesta a la Constitución y asentada en puestos claves continuaba reteniendo las riendas del poder e imposibilitando la implantación en ultramar del nuevo orden. Además, las reclamaciones de los ame-

6 El Americano Liberal, J. V.: Proclama de un americano á los insurjentes y demás habitantes de Nueva España. Méjico, Imprenta de Don Alejandro Valdés. Año de 1820 (Fondo Lafragua de la Biblioteca Nacional de México —en adelante, LAF-253).

7 El Mejicano independiente, 14-IV-1821, reproducido en García Díaz, Tarsicio: "La prensa insurgente", en Hernández, Octavio (ed.): La República Federal Mexicana. Gestación y nacimiento, 8 vols., México, 1974, vol. VI, t. 2, págs. 492-493. Este periódico había aparecido por vez primera el 3 de marzo, escasamente nueve días después de la proclamación del Plan de Iguala.

8 Reflexiones importantes al gobierno constitucional de America, núm. 2. México, Imprenta de D. J. M. Benavente y Socios. Año de 1820 (LAF, 250). 
ricanos para obtener una más equilibrada presencia de delegados del Nuevo Mundo en las Cortes no condujeron a ninguna parte.

Detrás de ese problema de la representación indiana en Cortes, subyacía, según advierte Miranda:

"una cuestión fundamental, de índole esencialmente política, la de la igualdad de derechos de peninsulares y ultramarinos; cuestión que constituía la entraña del llamado problema americano o a la cual se reducía en esencia éste [...] y por lo tanto, cuestión en cuyo torno girarían casi todas las demás, como giraron, en efecto, casi todas las otras que suscitaron colectivamente los diputados del Nuevo Mundo".

Tal vez la importancia concedida a la discriminación de los americanos en el órgano legislativo se explique por su inserción en la corriente de afrentas inferidas por los europeos a los americanos, que tanto herían la susceptibilidad de los criollos. ${ }^{10}$ Así, el sistema de diputados suplentes que se utilizó en los ya remotos tiempos de Cádiz, y que luego volvió a aplicar la Junta Provisional en 1820, fue impugnado desde el principio por los patriotas americanos, que consideraron ilegal la designación de esos representantes, puesto que no habían recibido el correspondiente encargo de sus provincias.

Menos aún satisfizo en Ultramar la normativa que rigió para el nombramiento de los diputados propietarios, que fue tachada de discriminatoria porque proporcionaba a América un número de escaños insuficiente y excluía a las castas del derecho al voto. Ese fracaso en la aceptación de las propuestas de las Cortes sancionaba el naufragio de la solución de compromiso que había dado origen al decreto de 15 de octubre de 1810, en virtud de la cual se aplazó para un futuro indeterminado la paridad en la representación parlamentaria de España y de ultramar. El problema, tal como lo entiende Rieu-Millán, estribaba en la imposible fusión de dos

9 Miranda, José: Las ideas y las instituciones políticas mexicanas, $1^{a}$ parte (1521-1820), México, 1978, págs. 230-231.

10 Villoro, Luis: El proceso ideológico de la revolución de independencia, México, 1977, págs. 132-140, y López Cámara, Francisco: La génesis de la conciencia liberal en México, México, 1988, pág. 56, donde se explica el desarrollo de la "conciencia criolla". Ésa era indudablemente la sensibilidad que traslucía una representación dirigida al virrey de la Nueva España, en 1821, en la que se reincidía en el agravio inferido a los americanos en este punto: "se les ha negado la representacion que les toca. ¿Cómo, pues, querer que los nacidos en este continente pasen por la rebaja de las castas, cuando no sucede lo mismo en España que tiene muchos descendientes de los africanos?" (Siurob, Juan José: Representación al Exmo. Señor Virey sobre la independencia de América. México, Oficina de D. José María Betancourt, calle de San José el Real núm. 2. Año de 1821. LAF, 769). 
cuerpos tan heterogéneos como España y América, sin que uno quedase subordinado al otro. ${ }^{11}$

Pese a la negativa experiencia acumulada en los últimos tiempos, no faltaban publicistas entusiastas partidarios de la unión con España. La consideración de las ventajas que, en su opinión, se seguirían para América de la revisión de los fundamentos del Gobierno español les inducía a legitimar la dominación española: "bajo este benéfico sistema, esta reconciliacion con la Península será, mas que dependencia real, una unión por recíproca conveniencia". ${ }^{12}$

Además, antes de reivindicar la emancipación de América parecía obligado examinar si se hallaba en condiciones de gobernarse por sí misma. Ahora bien, atendida su baja demografía y constatado el carácter escasamente ilustrado de la población y el atraso en agricultura, artes, manufacturas y comercio -concluía uno de los detractores de la independencia_-, "la América se halla muy distante del tiempo de su emancipación": era preciso olvidarse de este género de reivindicaciones, "que tanta sangre ha costado á nuestra querida Patria", y acogerse a las posibilidades abiertas por la reimplantada Constitución de Cádiz. ${ }^{13}$

El mismo Carlos María de Bustamante, en el primer número de $L a$ Abispa de Chilpantzingo, reconocía la inmadurez de los ideales independentistas. Veía ante sí sólo "el embrión de un pueblo libre", que necesitaba avanzar un largo trecho antes de alcanzar la meta soñada: "témome mucho, que prevenido con estas disposiciones pésimas se nos forme un mosaico deforme de legislacion y gobierno". ${ }^{14}$

11 Rieu-Millán, Marie-Laure: "Los diputados americanos en las Cortes de Cádiz: Elecciones y representatividad”. En Quinto Centenario, núm. 14, Madrid, 1988, págs. 53-72 (pág. 62). También Ferrer Muñoz, Manuel: La Constitución de Cádiz y su aplicación en la Nueva España (Pugna entre Antiguo y Nuevo Régimen en el virreinato, 1810-1821), México, 1993, capítulo 7, donde se trata extensamente de la representación americana en Cortes; Reyes Nevares, Salvador: "Las Cortes de Cádiz y las ideas políticas en México", en VV. AA.: Los Derechos del pueblo mexicano. México a través de sus constituciones, México, 1985, Historia Constitucional, vol. I, págs. 263-316 (págs. 278-281 y 297-300), que estudia los primeros problemas planteados en torno al número de representantes en Cortes que correspondía nombrar a América, y Hernández Sánchez, Alejandro: "Las Cortes de Cádiz y las actuaciones de los diputados americanos", en Ibídem, págs. 317-718 (págs. 376-417, 521-530, 555-561 y 571-582), que recopila las extensas intervenciones de diputados españoles y americanos en las Cortes, en torno a la cuestión de que venimos ocupándonos.

12 J. V.: Sobre la suerte de las Américas. Impreso en Madrid en la oficina de D. Francisco Martínez Dávila, impresor de Cámara de S.M. Y reimpreso en Méjico en la de D. Alejandro Valdés. Año de 1820 (LAF, 261).

13 Breves reflecciones sobre la independencia de América. Méjico, Oficina de los ciudadanos militares D. Joaquín y D. Bernardo de Miramón, calle de Jesús núm. 16. Año de 1821 (LAF, 253).

14 La Abispa de Chilpantzingo, núm. 1 (LAF, 206). 
En abierta discrepancia con esos juicios y a notable distancia en el tiempo, José María Luis Mora fundamentó el derecho del pueblo mexicano a constituirse como nación independiente en su madurez histórica, que le concedía "bastante fuerza para subsistir por sí mismo, no necesitado ya del apoyo que le había prestado su metrópoli”. Y, al definir las rémoras que incapacitaban a los pueblos para el acceso a la autonomía — lastres de los que, según Mora, México se había desprendido-, precisaba: "su debilidad, un terreno muy limitado, la falta de industria ó de capitales, las producciones del pais desconocidas ó todavía no apreciadas en el resto del globo; pero más que todo su despoblación y escasez de luces". A los ojos de Mora, la confluencia de esos factores en 1810 no desembocó en la independencia, porque el "poder Moral" - "el convencimiento de las ventajas de la independencia y el deseo de obtenerlas" - no era entonces sino patrimonio de unos pocos. Se hizo precisa la espera hasta 1821 porque "entonces aun la clase ínfima del pueblo conocía, apreciaba y deseaba los bienes consiguientes á la independencia". ${ }^{15}$

Eran también comunes las advertencias acerca de los amargos frutos que producía el árbol de la independencia: ${ }^{16}$ voz ésta "seductora", arraigada "en la imaginacion de hombres inconsiderados ó falaces"; $;{ }^{17}$ política aquélla de la que

"resulta que la masa general del Estado, para libertarse de los tiranos sin concepto que la oprimen, muda de mandantes por el camino de la violencia, hasta que viene á caer bajo la esclavitud de un solo hombre atrevido y mañoso que supo hacerse dueño de la fuerza armada". ${ }^{18}$

Hubo polemistas que rebajaron a los partidarios de la independencia a la categoría moral de "criminales y delincuentes", infieles al juramento de observancia de la Constitución española, y desagradecidos - "ingratos hijos, prostituidos y espureos"- a los sacrificios prodigados por España para la conservación y enriquecimiento de sus posesiones ultramarinas. ${ }^{19}$

15 Mora, José María Luis: "Catecismo político de la federacion mexicana”, en VV. AA.: Los Derechos del pueblo mexicano. Historia Constitucional, vol. II, págs. 307-351 (pág. 313).

16 Independencia. Amargos frutos que produce este árbol. México, Oficina de D. Juan Bautista Arizpe. Año de 1820 (LAF, 142). El tono excesivo de este folleto, que contenía bastantes afirmaciones peregrinas, mereció una réplica contundente: J. B. M.: Verdadera esplicacion de la voz independencia. Méjico, Oficina de D. Alejandro Valdés. Año de 1820 (LAF, 144).

17 Independencia. Amargos frutos que produce este árbol.

18 Ibídem.

19 La Independencia. México, Oficina de D. José María Betancourt, calle de S. José el Real núm. 2. Año de 1821 (LAF, 257). Las duras descalificaciones de este folleto suscitaron inmediatas réplicas, incluso de los sostenedores de los intereses de España: "olvidad el espíritu que respira ese papel 
Algunos de los partidarios de la pervivencia del dominio español proponían una profundización en el concepto de libertad, que previniera la comisión de ulteriores abusos por parte de los nuevos dueños de la situación, y es honrado reconocer, aun admitiendo la impopularidad de la tesis anti-independentista, que el tiempo reveló certero este tipo de advertencias, fundadas en un dicho de la sabiduría popular entonces común en México: "no hay peor cuña que la del mismo palo".

Preocupaba también la difícil sujeción a un mismo centro de poder de territorios muy dilatados. Uno de esos autores "españolistas" enfilaba sus críticas a "la astuta pluma del sofista Juan Jacobo Rousseau", cuyos escritos habían llegado a configurarse como referencias obligadas: para exaltarlos o para combatirlos.

"este impío en su Pacto social enseña que en tratándose de libertad é independencia, una provincia no debe sujetarse á otra, ni una ciudad á otra ciudad: cada una debe ser independiente y erigirse autoridades á su arbitrio; porque no encuentra razon para que un pueblo grande reconozca superioridad á otro cuando todos tienen en sí libertad é igualdad de derechos para hacerse sociedad sin dependencia agena, cuya dependencia tiene siempre el carácter de humillacion". ${ }^{20}$

La vertiente intimidatoria era muy del gusto de los publicistas inclinados en contra de la independencia que, una vez y otra, insistían en trazar cuadros cargados de sombras y de amenazas. Sólo que, en ocasiones, la naturaleza de esos supuestos peligros permanecía sin desvelarse. ${ }^{21}$

Por unánime que fuese la reivindicación de independencia — sostenía el irónico autor de Ventajas de la independencia-, ${ }^{22}$ apenas nadie llegaba a calibrar sus graves consecuencias a corto plazo: entre ellas, la necesidad de reforzar con hombres, armas y construcciones las extensas fronteras de la nueva nación.

titulado la Independencia. Su contenido os debe desengañar de que su autor no merece concepto alguno, y la mayor prueba que os puedo dar es, aseguraros del general desagrado que ha causado entre los europeos, quienes lejos de abrigar las ideas que en él se indican, desearían demostraros con hechos positivos que su afecto á vosotros es sincéro, que su único anhelo es el de restablecer el orden (M. J. U.: El amigo de españoles americanos y europeos. México, Oficina de D. J. M. Benavente y Socios. Año de 1821. LAF, 253).

20 Independencia. Amargos frutos que produce este árbol.

21 Para ejemplificar este tipo de argumentaciones, reproducimos un pasaje extraído de un impreso citado ya anteriormente (La Independencia): "un enemigo más poderoso os asecha que aguarda vuestro triunfo para reduciros á más dura y penosa esclavitud: ellos os harán arrastrar verdaderamente la cadena y con vuestro mismo oro labrarán los grillos que os sujetarán para siempre".

22 A. J. F.: Ventajas de la independencia. México, Imprenta de D. Mariano Ontiveros. Año de 1821 (LAF, 442). 
Los negros presagios sobre el futuro de una América emancipada, que se preveía irremediablemente envuelta en la anarquía, venían arropados de modo ocasional con consideraciones acerca del inmediato presente: el relevo del "incauto" Apodaca y la presencia en el Virreinato del "prudente y benéfico" O'Donojú aconsejaban deponer posturas rupturistas y entablar un confiado diálogo con ese "agente del actual Gobierno de España, liberal por esencia, y que tan generoso se muestra espontáneamente con nosotros". ${ }^{23}$ Ahora bien, muchos de quienes ensalzaban a O'Donojú abogaban por la separación: una independencia pactada y obtenida sin el recurso a las armas, pero independencia sin paliativos, por más que se invitara a los españoles a trabajar en la inminente regeneración de un país asolado por las guerras.

Más común era el punto de vista de los que, compartiendo el aprecio de la obra política llevada a cabo en América por España, entendían que era viable su culminación sin el trauma del rompimiento. Más aún,

"un sistema de gobierno sabio, justo y equitativo acababa de abrir las puertas de par en par á la comun felicidad, quitando las trabas que la oprimían, dando energía al cuerpo político del Estado y animando la industria por medio de una libertad absoluta á todos los ramos de ella". ${ }^{24}$

Eran, en consecuencia, tiempos de esperanza porque la virtualidad de las instituciones políticas de raigambre liberal aseguraba la equidad, contribuía a la reconciliación y desterraba los viejos abusos. En función de estas premisas, los promotores de la independencia venían denunciados como facciosos y nostálgicos de la opresión; con Iturbide a la cabeza -el "falso Iturbide"-, de quien se recordaban su anterior actuación, "tan impolítica y tan bárbara", sus irregularidades administrativas y su brutalidad:

"¿no es verdad que el que ahora quiere hacer el papel de héroe de la independencia, es el mismo que en menos de dos horas hizo derramar á balazos la sangre de mas de ciento y cincuenta desgraciados que querían lo mismo, dejando inundado en sangre el Valle de Santiago, teatro horrible de esta inhumana carnicería, y esto á sangre fria y sin permitir que estos infelices recibieran los auxilios de la Religión, que ahora este hipócrita dice viene á defender?"25

23 Noticioso general, 27-VIII-1821, núm. 103 (LAF, 126).

24 Liberales, alerta. México, Oficina de D. Juan Bautista de Arizpe. Año de 1821 (LAF, 439).

25 Ibídem. 
El descrédito que se quería arrojar sobre los caudillos de la emancipación corría parejo al empeño por destacar los lazos comunes a europeos y americanos, que constituían el fundamento de la común felicidad:

"tengamos presente que europeos y americanos todos somos españoles, dependemos de una nación grande y generosa, que profesamos una misma religión é idioma, que nuestros intereses están íntimamente enlazados, que hemos jurado ante el Omnipotente observar la Constitución, y ser fieles al mejor de los monarcas, que el augusto Congreso de Cortes se compone de españoles de ambos mundos, á quienes hemos conferido nuestros poderes, y que ellos promoverán cuanto convenga á la felicidad nacional", ${ }^{26}$

Quienes defendían estos criterios solían encomiar la figura de Apodaca — "un Virey íntegro, justificado y exactísimo en el cumplimiento de sus deberes"-, y no escatimaban alabanzas a su celo en el desempeño del cargo, al tiempo que vilipendiaban el plan sedicioso de Iturbide para "proclamar una independencia falaz é imaginaria". ${ }^{27}$ Por lo demás, la conducta y las resoluciones de Ruiz de Apodaca "para oponerse á las criminales ideas del coronel D. Agustin de Iturbide y sus partidarios" recibieron la aprobación del propio Consejo de Estado en el mes de junio de 1821. ${ }^{28}$

Sin embargo, el irregular relevo de Apodaca por Novella, en julio de 1821, "sorprendió a México, llenando de amargura á todo hombre de juicio y prudencia"; ${ }^{29}$ causó irreparables daños al Gobierno español que, tras ese acontecimiento, se vio privado de legitimidad, ${ }^{30} \mathrm{y}$ dio alas a renovados intentos autonomistas por parte del Ayuntamiento capitalino, que reclamó para sí el ejercicio de la soberanía. ${ }^{31}$

26 M. J. U.: El amigo de españoles americanos y europeos.

27 Un Incógnito: Advertencias de un americano incógnito á sus conciudadanos. México, Imprenta de Don Mariano Ontiveros. Año de 1821 (LAF, 253).

28 Noticia de la mayor importancia. Consulta hecha al Rey de España por su Consejo de Estado sobre la Independencia de América. México, Imprenta (contraria al despotismo) de D. J. M. Benavente y Socios. Año de 1821 (LAF, 207).

29 El Apuntador: Verdades en camisa o apuntes sobre la alteracion de humores que padeció el cuerpo político del Virreinato de México con motivo de la fiebre maligna y contagiosa de que murió aquel gobierno. Méjico, Imprenta de Mariano Ontiveros. Año de 1821 -LAF, 222 - (citado en Ocampo, J.: Las ideas de un día, pág. 170).

30 Ejército imperial Mejicano de las Tres Garantías, núm. 11, 13-VII-1821. El primer número de Busca pies tildaba de "cómico" al gobierno establecido por Novella, que sólo de un modo temerario y terco podía pretender resistir al "Gobierno legítimo de la América Septentrional [...], constituido por los Gefes del Ejército Imperial Mejicano de las Tres Garantías": Busca pies, núm. 1 (García Díaz, T.: "La prensa insurgente", vol. VI, t. 2, pág. 573).

31 Representación del Excelentísimo Ayuntamiento de Méjico al comandante accidental de las armas de la misma ciudad, Mariscal de Campo don Francisco Novella. Puebla, Imprenta del Gobierno Imperial. 1821 (LAF, 395), reproducida en Lemoine, Ernesto: "La revolución de independencia, 1808-1821", en Hernández (ed.): La República Federal Mexicana. Gestación y nacimiento, vol. IV, págs. 525-527. 
La proclama que, con el título "El nuevo Virey á los mexicanos", redactó Novella el 12 de julio tampoco consiguió disipar la desconfianza que en muchos inspiraba el peculiar procedimiento de su acceso al poder: la necesidad que parecía impulsar a Novella a justificar su presencia en el cargo que hasta entonces había desempeñado Apodaca restaba credibilidad a sus intenciones, por más que enfatizara su "amor y respeto á las sabias leyes que hoy felizmente nos rigen", y recordara "las pruebas mas completas de subordinación y respeto" que había dado en el desempeño de sus tareas como subinspector general de Artillería y gobernador de la plaza. ${ }^{32}$

Más aún: las referencias al "misterioso suceso de la noche del 5 del corriente", que había culminado en su designación como primera autoridad del reino, resultaban particularmente desacertadas, al ser presentado aquel acontecimiento como ocasión de que "la emulacion indiscreta de algunos, la necedad de otros y la astucia de nuestros enemigos" ${ }^{\prime 33}$ se sirvieron para desprestigiar la figura de Novella.

La vana apología de sí mismo y la autocomplacencia en su personal valía, supuestamente refrendada por la experiencia - "el yunque [donde] han de estrellarse los martillos de la detraccion"-, acababan de rematar el mal efecto de un documento redactado con tan notable torpeza.

La necesidad de colmar ese vacío de poder legal indujo a un Ciudadano Español a elaborar un plan que sometió a la Diputación provincial de México: solicitaba en él que no se aceptara la renuncia de Apodaca "porque es imposible encontrar otro en quien concurran las cualidades de general con las prendas de un politico"- y que, para atender al "negocio de los negocios", se reuniera un Congreso en México con los diputados recién elegidos para las Cortes españolas, con la finalidad de determinar la voluntad de la nación: la unión con España o la independencia. ${ }^{34}$

Incomunicado con Veracruz y consciente del progresivo deterioro de la resistencia realista, Novella publicó una violentísima proclama "á los egoistas de todas clases, condiciones y estados", que traducía un íntimo

32 Novella, Francisco: El nuevo Virey á los mexicanos, México, 12-VII-1821 (LAF, 424).

33 Ibídem.

34 El Ciudadano Español: El negocio de los negocios. Representacion urgentísima que dirige un Ciudadano á la excma. Diputacion Provincial de Méjico. Puebla, Oficina del Gobierno. Año de 1821 (LAF, 127). 
desasosiego y la convicción de que eran muy pocas las personas en que podía depositar su confianza. ${ }^{35}$

Los apologistas de la causa española, aún conscientes de la fragilidad de su postura, incomodada por la crisis en el mando virreinal, se esforzaban en probar la legitimidad de la conquista de México, sistemáticamente puesta en entredicho por el bando independentista, al tiempo que enumeraban los "vicios capitales del sistema de la independencia": la usurpación de los derechos del rey español; la carencia de una "voluntad general" manifiestamente decantada en favor de la ruptura, y de unas fuerzas armadas capaces de defender efectivamente la independencia nacional; la falta de dirigentes capacitados para regir los destinos de la nueva nación; la amenaza representada por el poderoso vecino del norte; el difícil hallazgo de un titular para la Corona en el caso, más que probable, de que Fernando VII declinase la oferta, etcétera. ${ }^{36}$

En esa enumeración de obstáculos y calamidades que acechaban cada paso de la ruta emancipadora era insistente el énfasis en los horrores de la anarquía, que había de ser evitada a toda costa: la amarga experiencia del levantamiento de Hidalgo _-"la sangre que aun humea", "el luto, la horfandad que por todas partes se presentó á nuestros dolientes ojos"- obligaba a prevenir sucesivas erupciones de "un horrible volcán que amenaza envolvernos en nuevos desastres". ${ }^{37}$

35 Vale la pena reproducir íntegro el texto de este documento: "vuestra criminal conducta no se oculta al Gobierno: veo con horror, que unos os habeis ausentado de la capital y escondido en los pueblos de su circunferencia; otros en vuestras casas, y algunos os habeis acogido á la sombra de nuestros enemigos. No contentos con este proceder tan inicuo, disparais cartas á los que llamais vuestros amigos convidándolos á obrar como vosotros; les aumentais la fuerza de nuestros contrarios; os pintais como se os antoja, ya para atemorizar, ya para confiar en su conducta; todo, todo es obra de vuestra cobardía, de vuestra avaricia y egoismo: pues calculasteis muy mal, estais proscriptos por todos los hombres, porque perdisteis el carácter de tales; volved á vuestro juicio, y tomad una resolución, ¡miserables! Yo no os llamo porque desconfío de vosotros; pero sí que no perturbeis la marcha de los buenos, porque este proceder os tiene hecha la causa en todos tiempos, en todas circunstancias y por todos los hombres, que conocen que sois de aquellos que no tienen mas pátria que querer conservarse á costa del sacrificio de sus semejantes: vedme, vedme combatido de tempestades con la frente serena arrostrando todo género de peligros: ¿y qué espero? la salvacion del reino, sin mas interés que el que digan algun dia, cumplió su deber". (Novella, Francisco: Proclama á los egoistas de todas clases, condiciones y estados. México, Oficina de D. Juan Bautista de Arizpe. Año de 1821. LAF, 424).

El contenido de la proclama se publicó también en territorio dominado por Iturbide, con una introducción dedicada a desacreditar la figura de Novella, y numerosas y extensas notas con apostillas sobre las afirmaciones que en la proclama hacía Novella; J. N. T.: A los señores oficiales y soldados del Ejército Nacional de las Tres Garantías. Puebla, Imprenta Liberal de Troncoso Hermanos. Año de 1821 (LAF, 393).

36 Colmena de las Abejas, núm. 3 (LAF, 416).

37 El Verdadero Liberal: Paz, unión, justicia y constitución. Méjico, Oficina de D. José María Betancóurt, calle segunda de la Monterilla, núm. 7. Año de 1820 (LAF, 143). 
Incomparablemente más decidida y abundante era la obra publicística en favor de la emancipación: las quejas presentadas en las Cortes españolas por los diputados americanos, ${ }^{38}$ el Plan de Iguala y los Tratados de Córdoba, proyectos, discursos y sermones, modestas aportaciones a la filosofía política... todo ello era trasladado por la prensa a conocimiento de la ciudadanía, y contribuía a crear un clima de opinión que, aparentemente, reflejaba una "voluntad general" inclinada a la independencia: "faltando, pues, la confianza mutua, y siendo implacable hoy el odio de españoles y americanos, se ha roto para siempre el lazo que unía las colonias á la metrópoli" ${ }^{39}$ al deshacerse el pacto que, por voluntad de ambas partes - americana y española-, unía tradicionalmente en la persona del monarca español los territorios de una y otra orilla del Atlántico.

El Gobierno de España había comprometido su legitimidad y pasado a la conceptuación de "despótico y tiránico" al actuar en beneficio exclusivo de "una sola clase", y dictar leyes y órdenes "contra la voluntad expresa de los Pueblos; y por consiguiente contra el bien comun. ${ }^{40} \mathrm{Y}$ sus delegados en México habían contribuido a ese desprestigio, sosteniendo órganos de prensa embusteros, como Gaceta del Gobierno de México ${ }^{4 l}$ y Noticioso general, "concediendo libertad amplia á sus autores para estampar en ellos

38 Papel que la Diputación Megicana dirige al Excmo. Señor Secretario de Estado y del Despacho de la Guerra. Impreso en Madrid por Ibarra, y en Puebla en la Oficina Liberal de Troncoso Hermanos. Año de 1821 (LAF, 955); y Ramírez, José Miguel: Nada hay que esperar de España, ó esposicion que leyó el Sr. D. [...] en la sesion del 25 de Junio de 1821. México, Imprenta Imperial de D. Alejandro Valdés. Año de 1821 (LAF, 254). Una consulta del Consejo de Estado, fechada el 11 de junio de 1821, recogía el rumor — al que no parecía conceder excesivo crédito- de que "los Diputados á Córtes han traido instrucciones para arreglar el modo de verificarla [la emancipación]": Noticia de la mayor importancia. Consulta hecha al Rey de España por su Consejo de Estado sobre la Independencia de América.

39 Infante, Joaquín: Solución á la cuestión de derecho sobre la emancipación de la América, por el ciudadano Joaquín Infante, natural de la isla de Cuba. Impreso en Cádiz, reimpreso en Puebla, y por su original en Mégico, en la oficina de D. José María Betancóurt, calle segunda de la Monterilla, núm. 7. Año de 1821 (LAF, 221).

40 Busca pies, núm. 1 (García: "La prensa insurgente”, vol. VI, t. 2, pág. 573).

41 La Gaceta del Gobierno de México protagonizó el más importante duelo con los periódicos insurgentes (después, con los trigarantes), y se configuró como instrumento de propaganda y defensa de la causa virreinal: a esa contienda ideológica y a la necesidad de neutralizar los efectos de la prensa enemiga quedaron supeditados los contenidos informativos (García: "La prensa insurgente", vol. V, t. 1, págs. 39 y 85). A pesar de los dicterios que por esta razón se atrajo la Gaceta, la realidad es que esa mediatización de las tareas periodísticas al servicio de objetivos partidistas se registró también, como era inevitable, en el bando independentista. Pese a los ataques que el Diario Político Militar Mejicano dirigía en este texto a la Gaceta, había disminuido para entonces la virulencia de las confrontaciones verbales, sobre todo de parte de los periódicos que promovían la independencia. La explicación que proporciona Tarsicio García es plenamente convincente: "acorde con el sentido de conciliación del Plan de Iguala, el periodismo trigarante no pudo ser de combate; es predominante en lo 
cuantas imposturas y dicterios dicta la maledicencia”, y restringiendo arbitrariamente "la libertad política de la imprenta, que disfrutabamos con arreglo a nuestro sistema constitucional". ${ }^{42}$

Según quienes invocaban la adhesión generalizada a la causa rupturista como razón para abandonar cualquier proyecto de continuidad bajo la dependencia española, los que se empeñaban en resistir eran apenas "un puñado de hombres casi ya sin recursos, sin opinion ni aceptacion", por lo que la "Independencia de nuestra América es un suceso indefectible que ha de verificarse tarde ó temprano", ${ }^{43}$ impulsado por "el voto unánime de sus naturales y habitantes", coincidentes todos en los anhelos independentistas: "criollos y europeos todos piensan y hablan en este sentido: todos anhelan por sustraerse del gobierno de Madrid". ${ }^{44}$

La mención de una voluntad general obligaba, evidentemente, a tomar en cuenta la circunstancia de la diversidad de razas que cohabitaban en la Nueva España. ¿Había de ser la reivindicación autonomista patrimonio común?, ¿debían constituirse los criollos como abanderados de la causa?: $\mathrm{y}$, en el caso de que se aceptara esta última alternativa, ¿qué papel correspondía a los indios y a las castas en el proceso de desvinculación de la metrópoli?, y ¿qué trato dispensar a los españoles avecindados en México?

Obviamente encontramos diversidad de respuestas a estos interrogantes. Con el tiempo prevaleció, sin embargo, el protagonismo criollo, tenden-

informativo. La justificación en la causa se argumenta tratando de no ofender a España; y no entra a la polémica que con insistencia trató de provocar la Gaceta de México [...] El contenido de la prensa trigarante se reduce en el campo ideológico a exponer las condiciones de la conciliación; de lo que era necesario ceder para evitar un mal mayor" (García: "La prensa insurgente", vol. V, t. 1, págs. 41 y 65).

42 Diario Político Militar Mejicano, 1-IX-1821, núm. 1 (García: "La prensa insurgente", vol. VI, t. 2, págs. 580-581). Miquel i Vergés llamó la atención, en su momento, sobre la peculiar orientación política de algunos artículos de este periódico, que exaltaban la labor de las Cortes gaditanas, objeto de tantas críticas entre los trigarantes; y de ahí concluía que su redacción parecía obedecer "al impulso de los ideales que iniciaron la contienda en 1810" (Miquel i Vergés, J. M.: La Independencia Mexicana y la Prensa Insurgente, México, 1941, pág. 308). En la misma obra encontramos una frase que recoge idéntico pensamiento con una mayor rotundidad, y que sugiere una interesante línea interpretativa, pendiente de ulterior verificación: "son tantos los comentarios apologéticos a los mártires de 1810 que ... se llega a pensar si la intención de algunos jefes no era la de enlazar el movimiento de Iturbide con el de Hidalgo" (ibídem, pág. 312). Sobre la aplicación en la Nueva España de la libertad política de imprenta, véase Ferrer, M.: La Constitución de Cádiz y su aplicación en la Nueva España, capítulo 5, y Neal, Clarice: "Freedom of the Press in New Spain, 1810-1820", en Benson, N.L. (ed.): Mexico and the Spanish Cortes, 1810-1822, Austin - Londres, 1966, págs. 87-112.

43 M. O. de T.: Exhortacion cristiano-política, dirigida á la Capital del Imperio Mexicano, y á todos los que sostienen el partido nombrado la Integridad de las Españas, Texcoco, Imprenta liberal de las Tres Garantías de Don Cayetano Castañeda. Año de 1821 (LAF, 256).

44 El Mejicano independiente, t. I, "Introducción”, Año de 1821, Primero de la Independencia (García: "La prensa insurgente”, vol. VI, t. 2, pág. 440). 
te a configurar una sociedad análoga en todo a la colonial: eso sí, libre y purificada de las discriminaciones que durante tres siglos habían favorecido a los españoles peninsulares y cerrado muchas puertas a los americanos.

Las reflexiones teóricas concedían, en cambio, idéntica responsabilidad e idénticas oportunidades a todos los habitantes de la Nueva España, llamados todos ellos a formar un cuerpo político capaz de integrar a indios y castas, y a españoles americanos y europeos. La inclusión de estos últimos, que se hallaba en la base del Plan de Iguala y de los Tratados de Córdoba, obedecía a razones que entonces parecían incontrovertibles. Así se explicaba el arcediano de Valladolid de Michoacán, Manuel de la Bárcena: "estando radicados aqui por sus destinos, por sus propiedades, y por sus enlazes, miran á la Nueva España como à patria suya, que ellos han elegido". ${ }^{45}$

Rafael Dávila distinguía entre españoles amigos de la independencia y españoles que hostilizaban la realización del proyecto emancipador; y proponía que se recompensara a los primeros, mientras que se declaraba enemigo de los "muchísimos españoles que hablan de la independencia con desprecio", a los que se debería exigir un juramento para que, "eligiendo por su patria nuestro suelo, se comprometan á defenderlo de enemigos y guardar sus leyes". ${ }^{46}$

Fernández de Lizardi expresó opiniones semejantes a las de Dávila, y manifestó sus dudas sobre la oportunidad de extender la garantía de unión a los españoles que no se habían mostrado adictos a la independencia: y, como solía ocurrir con muchas de sus publicaciones, arrastró en la polémica a otros varios escritores, que coincidieron con él en una aplicación restrictiva de las promesas de Iguala. ${ }^{47}$

La apertura hacia los europeos imponía, forzosamente, un rechazo del primer movimiento insurreccional, "marcado con las señales más funestas", que presagiaba acontecimientos desastrosos como los "que han asolado nuestra tierra, y arruinado un sinnùmero de fortunas". ${ }^{48}$ En consecuencia, la

45 Bárcena, Manuel de la: Manifiesto al mundo. La justicia y la necesidad de la independencia de la Nueva España. Puebla, Imprenta Liberal de Moreno Hermanos. Año de 1821 (LAF, 442 y Centro de Estudios de Historia de México, CONDUMEX, Fondos Virreinales, XLI-1, carpetas 17-24, núm. 1.248).

46 Dávila, Rafael: La verdad amarga, pero es preciso decirla, núm. 6. Méjico, Imprenta Americana. Año de 1821 —LAF, 257- (citado en Ocampo, J.: Las ideas de un día, pág. 184).

47 Ocampo, J.: Las ideas de un día, págs. 184-185.

48 El Mejicano independiente, t. I, "Introducción", en García: "La prensa insurgente", vol. VI, t. 2, pág. 439 . 
revolución de 1810 no podía ser tachada sino de desorganizada y anárquica, "impolítica y desastrada", y contemplada con hostilidad por los artífices del renovado impulso independentista, que nada tenían en común con los impulsores de los desórdenes de la anterior década: los dirigentes de 1821 "son los mismos que justamente se opusieron y la sofocaron [la revolución de 1810], y por lo tanto no hay que esperar los mismos resultados". ${ }^{49}$

En ese sentido, el autor de Justicia de la independencia dirigía las siguientes reflexiones a los españoles europeos:

"españoles europeos, la nacion os jura no volverán á molestar vuestros oidos las espantosas voces que os afligieron en los tiempos primeros de nuestra insurreccion. Nuestras lágrimas corrieron al par que las vuestras al contemplar delito tan enorme, y muchos de los nuestros libraron á costa de las suyas vuestras presiosas vidas del infernal cuchillo. Por ventura nuestra aquellos tiempos de horror desaparecieron para siempre: los Americanos todos garantizan sobre la fè pública vuestra felicidad: uníos á nosotros por los mas indisolubles vínculos; vuestra patria no debe ser aquella que simplemente os vio nacer: este nombre debeis sin duda concederlo á aquel pais que os favorece con su benigno influjo, y que os ha dado cuantas comodidades disfrutais. Si, españoles: contribuid á nuestra felicidad: la America soberana es, puede dar cuanto jamas podria daros la Europa toda: tranquilizad vuestros ánimos: reflexionad con atención sobre vuestro verdadero interés: no cerreis los ojos para no ver los repetidos ejemplares de generosidad y virtud, que diariamente os presentan los ejércitos Americanos. Unión íntima é indisoluble con vosotros; hè aqui uno de sus mas gloriosos empeños. ¿Será posible que vosotros mismos rompais este vínculo de amor y gratitud, con que la misma naturaleza os ha unido con nosotros para siempre?"'50

Por contraste, el Diario Político Militar Mejicano prorrumpía en elogios a los "héroes ilustres" de 1810, "las almas venerables de los Hidalgos, Allendes, y Aldamas, de los Morelos, Matamoros, y Bravos", a quienes atribuía el mérito de haber asentado los cimientos de la independencia y a quienes estimaba como "compatriotas" del invicto Iturbide: por consiguiente, nunca habría motivos de cansancio para dejar de "bendecir vuestra resolución en el grito de Dolores en 1810, de reconocer vuestro acendrado patriotismo, de elogiar vuestra heroicidad, y de inmortalizar vuestros nombres". ${ }^{51}$ Alabanzas éstas que necesariamente comportaban la concien-

49 Ibídem, 2-VI-1821, en García: "La prensa insurgente”, vol. VI, t. 2, pág. 520.

50 Justicia de la independencia, ó apuntamientos sobre los derechos de los americanos. Méjico, Oficina de D. José María Betancur. Reimpreso en Guadalajara. Año de 1821 (LAF, 1.417).

51 Diario Político Militar Mejicano, 17-IX-1821 (García: "La prensa insurgente", vol. VI, t. 2, pág. 652). La misma actitud reivindicadora de las actuaciones de los primeros insurgentes puede apreciarse en un anónimo que apareció en 1821: Carta de un filósofo sobre los últimos acaecimientos políticos. Méjico, Imprenta Imperial. Año de 1821 - LAF, 210_- (citado en Ocampo, J.: Las ideas de un día, pág. 164). 
cia de que España seguía siendo el enemigo contra el que los hombres de 1810 se habían batido y contra el que se hallaban en plena lucha los de la nueva generación emancipadora.

El mismo Iturbide, que nunca simpatizó con la causa insurgente, no pudo prescindir de la adhesión de sus caudillos supervivientes, auroleados de prestigio popular, y no dejó de reconocer - aunque en sordina- que la toma de conciencia por la emancipación se debía a la insurgencia de $1810 .^{52}$

Una postura intermedia, respetuosa con una y otra de las etapas de la independencia, era la sostenida por Francisco Luis Ortega en su melodrama México libre, donde ensalzaba las figuras de Hidalgo, Matamoros y Morelos, e incluía un cálido panegírico de la persona de Iturbide, activo, prudente, sabio y "acostumbrado al rudo afán". ${ }^{53}$

Pero la realidad, crudamente expuesta por Ernesto Lemoine, es que la incompatibilidad de planteamientos entre los hombres de 1821 y sus antecesores de 1810 impedía alumbrar un proyecto conjunto: "en aras de liquidar una situación insostenible, todas las fuerzas que entraron en juego ‘transaron', pero a sabiendas de que la dicotomía axial (1810 versus 1821) quedaba en pie, y que el conflicto habría de reanudarse desde el día siguiente al de la 'liberación' de la capital". ${ }^{54}$

Con frecuencia se pretextaban el "mal gobierno" y el despotismo y lo irremediable de esos hábitos defectuosos, para justificar la necesidad de emprender una vida política propia, no mancillada por vicios tan arraigados. ${ }^{55}$ Muchas veces se proponía la independencia como si fuese un elixir mágico, que desterraría de una vez por todas la desidia del gobierno, la corrupción de los funcionarios, las discriminaciones raciales, la impiedad en que parecía empeñada en precipitarse España desde que penetraron en la Península las ideas liberales... Y se otorgaba a la emancipación un signi-

52 García: "La prensa insurgente", vol. V, t. 1, pág. 66, que se vale del texto aparecido en $E l$ Mejicano independiente, 3-III-1821.

53 Ocampo, J.: Las ideas de un día, págs. 166-167.

54 Lemoine, Ernesto: “1821: ¿Consumación o contradicción de 1810”, en Secuencia, Revista Americana de Ciencias Sociales, núm. 1, marzo de 1985, págs. 25-35 (pág. 34).

55 Un escrito dirigido al secretario de la Gobernación de Ultramar por los diputados en Cortes de Nueva España, fechado el 8 de agosto de 1821, aludía explícitamente a esas deficiencias de la acción gubernativa de España en América como una de las causas de "los disgustos de nuestra patria": "el gobierno despótico, injusto y arbitrario que hubo y aun oy existe de echo en las Américas. Sus magistrados, sus Gefes y sus empleados, fuéron y son los que han dado la ley; esta estaba, y aun está en su capricho, no en los codigos: se ha dicho por muchos de ellos publicamente y en todos tiempos, aqui nosotros somos los unicos legisladores" (Delgado, Jaime: España y México en el siglo XIX, 3 vols., Madrid, 1950, vol. III, págs. 31-35 (pág. 32), documento V, "Escrito dirigido por los diputados a Cortes de Nueva España al secretario de la Gobernación de Ultramar”). 
ficado fundacional —el de un nuevo nacimiento-, como si el pueblo mexicano resultara fruto de un embarazo que se había prolongado entre 1810 y $1821 . .^{56}$

Los escribanos nacionales, que se decían respaldados por más de mil cuatrocientas personas de Puebla, reaccionaban contra la influencia de la Ilustración francesa en España y vituperaban a los "patriarcas de la incredulidad" —D'Alembert, Voltaire...—, con quienes se había aliado el conde de Aranda para "acabar con la religion de J. C." y expulsar a los jesuitas. ${ }^{57}$

Manuel de la Bárcena aludía explícitamente al escándalo suscitado en la Nueva España por la legislación religiosa de las Cortes del trienio, que chocaba con los hábitos mentales y las categorías de valores imperantes en el otro extremo del Atlántico:

“acá no está la opinión tan abanzada como en la Europa, por eso la violenta extinción de tantos Conventos religiosos, y el impolitico desafuero del Clero, han escandalizado al pueblo, han irritado á los Ecleciásticos, y han sido causas impulsivas del actual rompimiento". ${ }^{58}$

Era natural, por consiguiente, que Iturbide — defensor de la garantía religiosa - fuera exaltado por haber atraído las bendiciones del Cielo, y aplaudido como enviado de Dios, héroe de la religión, columna de la Iglesia, nuevo Moisés dador de libertad a un pueblo favorecido por la Providencia que, puesto a prueba, había sido esclavizado y oprimido. ${ }^{59}$

El análisis del mal gobierno era inseparable del balance económico de la colonización que, en el sentir de algunos críticos, sólo podía ser juzgado de un modo muy desfavorable, puesto que los beneficios de la empresa llevada a cabo por España en América habían sido patrimonio de unos pocos:

56 Esa interpretación es refutada por Bernardino Bravo: "la verdad es muy distinta. Cuando adoptaron el constitucionalismo, en la época de la independencia, [los pueblos hispanoamericanos] eran países con trescientos años largos de historia”. Bravo Lira, Bernardino: El Estado constitucional en Hispanoamérica 1811-1991. Ventura y desventura de un ideal Europeo de gobierno en el Nuevo Mundo, México, 1992, pág. 3.

57 Los Escribanos Nacionales: Defensa de los Padres Jesuítas por los Poblanos. México, Oficina de D. Pedro de la Rosa. Año de 1820 (citado en Bachman, J. E.: "Los panfletos de la independencia”, págs. 526-527 y 529). Algunas noticias sobre los incidentes registrados en Puebla cuando Ruiz de Apodaca publicó el decreto de Cortes por el que se suprimía la Compañía de Jesús, en Ferrer, M.: La Constitución de Cádiz y su aplicación en la Nueva España, págs. 82-84.

58 Bárcena, M.: Manifiesto al mundo.

59 Ocampo, J.: Las ideas de un día, págs. 56, 73 y 154. 
"la nación española sólo indirectamente, por el momento y con daño imponderable de sus verdaderas riquezas se há aprovechado de las ventajas de la América, mediante la circulación del dinero procedente de aquellos canales. Conviene inculcar al pueblo español esta verdad, que los comerciantes han procurado ofuscar por su interés, erigiendo en principio un error político perjudicial á la felicidad de ambos mundos [...] Los comerciantes gritan que se les escapa la América, objeto exclusivo de sus especulaciones, y que no pueden vivir sin que siga uncida al carro de la servidumbre. La nacionalidad, la fortuna y el bienestar de mas de quince millones de almas deben, pues, sacrificarse á un puñado de monopolistas á expensas de la sangre de sus hermanos de ambos mundos". ${ }^{60}$

Ni siquiera la misma abundancia de metales preciosos que proporcionaba América había compensado los efectos negativos de su masiva afluencia a la Península: "teniendo plata y oro conque comprar á los extrangeros, abandonaron los talleres que se arruinaron con el tiempo", sin que pudiera evitarse que ese flujo de riquezas acabara en manos extrañas. ${ }^{61}$

En la percepción de algunos escritores, el mismo hecho de hallarse establecido en España un régimen liberal, si bien parecía precaver la recaída en los hábitos de mal gobierno, avalaba —o, al menos, favorecía- la escisión de las antiguas colonias: pues, ¿cómo podría justificarse que un país regido por instituciones liberales enviara tropas para combatir opiniones parecidas a las que habían triunfado en la Península?, ¿cómo imponer a los naturales de América "las mismas cadenas que los buenos españoles tratan de romper"? ${ }^{62}$

Los liberales españoles, aun partidarios de la unión, entendían que ésta no podía ser impuesta bajo coacción. Así se expresaba Flores Estrada en 1818: "mi deseo de que las Américas formen una misma Nación con la España, debe entenderse siempre que sea compatible con la libertad, con los intereses, y aun con el voluntario consentimiento de aquellas, y no de otro modo". ${ }^{63} \mathrm{Y}$ un liberal mexicano, alineado con quienes así pensaban en España, expresaba su consternación ante el movimiento de Iturbide: "¿para qué pelear por la libertad y la independencia", si la Constitución de 1812 aseguraba que la nación española "es libre é independiente"? ${ }^{64}$

60 Infante: Solución á la cuestión de derecho sobre la emancipación de la America.

61 Siurob: Representación al Exmo. Señor Virey sobre la independencia de América.

62 Infante: Solución á la cuestión de derecho sobre la emancipación de la America, y Flores Estrada, Álvaro: Profecías políticas á favor de nuestra independencia. O Justificación de ella en razon al despotismo del Gobierno Español, sacada de la representación que hizo al Rey de España en 1818, desde la ciudad de Londres D. Alvaro Flores Estrada. México, Imprenta (contraria al despotismo) de D. J. M. Benavente y Socios. Año de 1821 (LAF, 242).

63 Flores: Profecías políticas á favor de nuestra independencia.

64 Un Incógnito: Advertencias de un americano incógnito á sus conciudadanos. 
La falacia parcial de esos argumentos estriba en que, al menos en el caso particular de la Nueva España, el movimiento emancipador de los años veinte se arropaba — en parte - con una ideología antiliberal y, si se promovía para asentar un régimen constitucional, también eran perceptibles los recelos hacia las nuevas instituciones de muchos de sus partidarios. Lo que, tal vez, no entendían los liberales es que la lucha de los insurgentes por la independencia carecía, en buena medida, de aspiraciones políticas vinculadas al liberalismo, y conectaba más bien con la vieja aspiración de autogobierno.

Sí era más cierta la imposibilidad en que se veía España para disponer de tropas que combatieran en América; por lo demás, la experiencia de lo ocurrido en Cabezas de San Juan en enero de 1820 disuadía de preparar cuerpos expedicionarios acerca de cuya disciplina cabía abrigar serias dudas.

$\mathrm{Al}$ analizar las publicaciones de la época tendentes a la ruptura con la metrópoli, llama la atención la falta de consistencia intelectual y de coherencia ideológica de que adolecen muchos de esos escritos: es frecuente que las mismas personas que difunden sus ideas al amparo de la libertad de imprenta (una libertad que aceptan y proclaman), pregonan la soberanía nacional y enfatizan la igualdad de todos ante la ley, califiquen de impías o disparatadas las pretensiones de las Cortes españolas de suprimir los fueros eclesiástico y militar, o de abrogar la exigencia civil de los diezmos.

Esas contradicciones se explican por la pervivencia en la Nueva España, como en el resto de la América española, de las doctrinas escolásticas - ya arrinconadas en los países europeos más avanzados-, algunas de las cuales - las teorías pactistas, por ejemplo- proporcionaban una justificación del patriotismo criollo y de los movimientos emancipadores. ${ }^{65}$

Se tiene la impresión de que nos movemos en los límites entre Antiguo Régimen y Modernidad - unas fronteras muy fluidas todavía- y de que los factores determinantes en la alternativa que se ofrecía a los novohispanos eran más de orden práctico que especulativo. En palabras de un Joven americano, "ninguna clase de gobierno puede hacer prosperar á las naciones americana y española, mientras la primera dependa de la segunda":66

65 Stoetzer, Carlos: "Los países de la Plata (Argentina, Paraguay, Uruguay) y Chile", en VV. AA.: La Revolución Francesa y el Mundo Ibérico, Madrid, 1989, págs. 329-330.

66 A. de R.: La necesidad de la independencia demostrada por un joven americano. Méjico, Oficina de los ciudadanos militares D. Joaquín y D. Bernardo de Miramón, calle de Jesús núm. 16. S. a. (LAF, 221). Nótese la precisión que el propio autor introduce más adelante sobre lo que él concibe como "nación americana": ésta "no puede ser otra cosa que el conjunto ó reunión de todos los individuos nacidos y residentes en America, ya traigan su origen de Africa, de España ó de Francia, etc.”. 
sólo el autogobierno permitiría la defensa efectiva de los intereses americanos y el logro de "la perfeccion de las ciencias, de la agricultura, del comercio y de las artes". ${ }^{67}$

Desde la perspectiva de la Modernidad sobresale la reiterada mención de los derechos del hombre - "generales y eternos"- para fundamentar el carácter ominoso $-\mathrm{y}$ por ello transitorio ${ }^{-68}$ de la dominación española, desconocedora de los presupuestos básicos de todo gobierno: "los pueblos pertenecen á si mismos y contra su voluntad no pueden ser constituidos por otro, pues el derecho de legislar se concentra más, cuanto más se trabaja por arrancarlo". ${ }^{69}$

También era común invocar la ruptura del pacto social que ligaba América con España (entendida la noción de pacto desde unos planteamientos acordes con la tradición escolástica): si los habitantes de aquella orilla del océano habían cedido parte de su libertad individual para constituir un gobierno que velara por su seguridad, fue precisamente "bajo la condición de que este gobierno consulte unicamente á la pública utilidad". ${ }^{70}$ La tiranía y la opresión determinaban la disolución de tal vínculo, por lo que los ciudadanos quedaban liberados de la obligación de obedecer:

“disolvióse por tanto justamente el vínculo de nuestra unión: devolvióse á la universalidad el derecho de gobernarse, y á ella unicamente pertenece establecer el gobierno que más le fuere conveniente. La utilidad pública clama enérgicamente por la absoluta emancipación è independencia de las Américas respecto de la antigua España; luego está demostrado con la mayor claridad, que la independencia de la América no puede ser mas justa, aun quando la España poseyese el más justo título para dominarla". ${ }^{71}$

El obispo Antonio Joaquín Pérez encarna en su persona tal vez como pocos esa paradoja entre el apego a las viejas concepciones y la apertura a los nuevos tiempos. En el discurso que pronunció el 5 de agosto de 1821 en Puebla de los Ángeles, para conmemorar la independencia, encontramos esa misma dualidad de principios: abrazaba la terminología en boga, al aludir a la ruptura del pacto con España, que restituía al "rei-

67 Ibídem.

68 J. M. C.: Reflexiones sobre la independencia. Reimpresas en Guadalajara, Oficina de Don Mariano Rodriguez. Año de 1821 (LAF, 1.417).

69 Ibídem.

70 Justicia de la independencia, ó apuntamientos sobre los derechos de los americanos.

71 Ibídem. Otra mención explícita de la ruptura del pacto y del retorno a las Indias de la plena libertad para constituirse, en Bárcena: Manifiesto al mundo. 
no de Nueva España á la libertad que le concedió la naturaleza"; y, más adelante, lamentaba los ultrajes que la legislación constitucional deparaba a la religión. ${ }^{72}$

Precisado el concepto de independencia como "la facultad que tiene una nación para salir de la dominación de otra, entónces será buena ó mala, según las circunstancias y ventajas, que pueda sacar de ser gobernada por sí misma, ó por la nación dominante": $:{ }^{73}$ otra vez, por tanto, el mismo enfoque empírico a que aludíamos más arriba. Así quedaba justificada la independencia a los ojos de muchos, a quienes parecía imposible el funcionamiento en América del sistema de representación nacional previsto en la Constitución española. Los inconvenientes planteados por las excesivas distancias saltaban a la vista:

\begin{abstract}
"es muy difícil, y casi imposible mantener el sistema representativo, sobre el pie en que está: los diputados de España no tienen que dejar sus casas, mas que tres ó cuatro meses al año, y aun en este corto tiempo, pueden desde Madrid atender á sus intereses; pero los de America han de abandonar sus familias, han de sufrir una ausencia de tres años, á una distancia de casi medio mundo: agréguense los gastos de tan dilatado viaje, y la dificultad de los transportes, por la suma escasez de la marina española: asi hemos visto en las actuales cortes, que para la primera legislatura no tubimos ningún diputado legítimo, y sólo un mesquino número de suplentes, faltos de poderes: para la segunda de cincuenta y seis nombrados, apenas seis habrán asistido; unos por su poca salud, ó por su mucha edad, no se atrevieron á emprender tan larga peregrinacion; otros se volvieron desde Veracruz; otros desde La Habana, por temor á los corsarios, ó por falta de barcos....". ${ }^{74}$
\end{abstract}

Ese pragmatismo inspira también algunos argumentos dirigidos a modelar la opinión, persuadiéndola de la utilidad que para España y sus posesiones americanas reportaba una pacífica desvinculación:

“¿no sería mejor y le traería más utilidad á la península el dejar á la América independiente, aliada y amiga, sacando de ella cuanto provecho pudiera al tiempo de declararle su emancipación, que el perderla, conquistada por otra nacion?’’75

72 Pérez Martínez, Antonio Joaquín: Discurso pronunciado por el Illmo. Sr. Dr. D. Antonio Joaquín Pérez Martínez, obispo de la Puebla de los Ángeles, entre las solemnidades de la misa que se cantó en la catedral de la misma el día 5 de Agosto de 1821 acabada de proclamar y jurar la independencia del Imperio Mejicano. Puebla, Oficina del Gobierno Imperial. Año de 1821 (LAF, 811 y Centro de Estudios de Historia de México, CONDUMEX, Fondo LXII-2, Impresos de la Independencia, Colección Martín Carracedo).

73 J. B. M.: Verdadera esplicación de la voz independencia.

74 Bárcena, M.: Manifiesto al mundo.

75 J. B. M.: Verdadera esplicación de la voz independencia. 
Análogas consideraciones de interés práctico se sitúan en la base de la casi general aceptación del régimen monárquico como el más indicado para una pacífica transición hacia el futuro nuevo Estado independiente: si bien el modelo republicano federal de los Estados Unidos de Norteamérica ejercía poderosa atracción, la forma política monárquica parecía más indicada para México, por tradicional, para serenar los ánimos inquietos de muchos ante el imprevisible rumbo del país, separado ya de España. ${ }^{76}$ Sólo algunas voces discrepantes insinuaban las excelencias del régimen republicano:

"cual sea mejor género de gobierno, no es para tratarse con sofismas. Son muchas las razones que hay por una y por otra parte; y si el monárquico tiene escelentes fundamentos, quien sabe si sobrepujarán á los del republicano [...] La esperiencia nos ha enseñado la preferencia de este género de gobierno respecto del monárquico [...] La razón no lo persuade ménos porque siendo la virtud mas dificil de practicar, mientras mayores sean las obligaciones anexas á su ejercicio, cuando vemos que es tan rara en los hombres corrientes, ¿será común en unos hombres, que por su educación, por los objetos que los rodean desde su infancia, y por mil circunstancias, están por decirlo así, casi necesitados á separarse, ó cuando ménos á desconocer el camino de la virtud? ¿Cual es el resorte principal de una república? El amor á la pátria: ¿y el de una monarquía? El honor. Aquel es una virtud; este un fanatismo. ¿Cual es mas noble?"77

Teresa de Mier, ferviente republicano, adelantaba su convencimiento de que una monarquía en México sucumbiría necesariamente bajo el peso de la autoridad absoluta, y sostenía que los tres siglos de opresión monárquica ahorraban ulteriores razones en apoyo de sus tesis antimonárquicas. ${ }^{78}$

El Observador Independiente, aun reconociendo el gobierno republicano como "el mas alahueño para el hombre", no dejaba de reconocer los peligros que lo acechaban: la enorme extensión del territorio mexicano; la necesidad de una mayor instrucción entre los ciudadanos, "por ser los que deben desempeñar los destinos"; el peligro de la propagación de conmociones, tan frecuentes en este tipo de regímenes, y la falta de garantías de los medios de coerción, muchas veces aplicados en daño de los virtuosos. ${ }^{79}$

76 Naturalmente, no dejaba de haber quien opinaba exactamente lo contrario: "las monarquías no son compatibles ni con las luces, ni con los sentimientos, ni con circunstancia alguna de los pueblos americanos": P. M.: El Genio de la Libertad (a los ciudadanos de las provincias de Guatemala). Méjico, Imprenta Americana. Año de 1821. Reimpreso en Puebla —LAF, 260— (citado en Ocampo, J.: Las ideas de un día, pág. 200).

77 J. B. M.: Verdadera esplicación de la voz independencia.

78 Ocampo, J.: Las ideas de un día, págs. 200-201 y 203.

79 F. E. y A.: El Observador Independiente. S. 1., Imprenta del ejército Imperial Mejicano. Año de 1821 (LAF, 210). 
Incluso personas como Lorenzo de Zavala, que más adelante destacarían por sus convicciones republicanas, compartieron el criterio de que debían sacrificarse momentáneamente las "pretensiones partidarias de los que querían la república, y de los que deseaban la monarquía absoluta. Todos los hijos del país se unían en el principio de nacionalidad; cada uno reservaba para después sus pretensiones diferentes". ${ }^{80}$

No parece desatinado pensar que la renuncia a la defensa de los postulados republicanos podía estar motivada por la conciencia de que esa predilección era aún sentida por muy pocos. La amplísima difusión de la obra de Dominique de Pradt, que estimaba la monarquía constitucional moderada como la plasmación del espíritu político del momento y, consiguientemente, como el régimen más adecuado para México, contribuyó tal vez a enfriar los ánimos republicanos. ${ }^{81}$

Tampoco era el momento de airear las aspiraciones federalistas. Por lo mismo que se aceptaba pacíficamente el sistema monárquico, se entendía que el entero territorio sometido a la autoridad de los antiguos virreyes constituía un todo que, como tal, había de configurarse como entidad autónoma. Incluso regiones que, como Nueva Galicia, se convertirían en seguida en auténticos avisperos donde se desafiaba la supremacía de las instituciones centrales establecidas en la ciudad de México, acataban la "resurrección" del Imperio del Anáhuac para que "haciéndose uno este Reyno con el de N. E. quede separado perpetuamente de la antigua España". ${ }^{2}$

80 Zavala, Lorenzo de: Ensayo histórico de las revoluciones de México desde 1808 hasta 1830, México, 1969, págs. 87-88.

81 Ocampo, J.: Las ideas de un día, págs. 194-195.

82 Peimbert, Juan Nazario: Desafío literario sobre la independencia de la América Septentrional de la antigua España. Por el Licenciado D. Juan Nazario Peimbert, Vice Rector del Ilustre Colegio de Abogados de Mejico. Guadalajara, Oficina de D. Mariano Rodriguez. Año de 1821 (LAF, 769). Conviene precisar que en esas fechas existían dos entidades con el nombre de Nueva España: desaparecido formalmente el Virreinato por la Constitución, el virrey quedó convertido en capitán general del territorio abarcado por el antiguo Virreinato de Nueva España, y jefe político superior de la Diputación provincial de Nueva España, que se correspondía con el antiguo reino de Nueva España y que incluía las provincias de México, Puebla, Oaxaca, Veracruz, Tlaxcala y Querétaro (por entonces se segregó la Diputación de Valladolid, que extendía su área de acción a Michoacán y Guanajuato). La presión de la delegación americana en Cortes logró que, en mayo de 1821, el Soberano Congreso dispusiera la concesión de diputaciones provinciales a todas las intendencias ultramarinas. Ese decreto de Cortes, fechado el 8 de mayo, llegaba sin embargo demasiado tarde, pues cuando su portador —el nuevo virrey O'Donojú- arribaba a Veracruz con el texto de estas disposiciones, la casi totalidad de Nueva España se había separado de la obediencia del Gobierno español. 
En nombre de ese mismo buen sentido, la Gaceta Patriótica del Ejército Nacional —en su número 26, del 21 de abril de 1820 - disuadía del empleo de la fuerza para alcanzar los objetivos de autogobierno, y recomendaba confianza en la resolución que adoptaran las Cortes: "entretanto procuremos acallar las pasiones, y tratemos de inspirar confianza á aquéllos con cuyo auxilio contamos para la grande obra de la conciliación de ambos paises". ${ }^{83}$ Naturalmente, el parecer de la Gaceta Patriótica, que muchos juzgaban de transigente en extremo, se prestaba a encendidas críticas, que veían detrás de esa propuesta a "hombres débiles, sin energía, sin sentimientos, que acomodando todas sus ideas al frio eterno que reina en la helada región de sus cerebros, no encuentran obstáculo en que un asunto, como este, por su naturaleza ejecutivo, siga los lentos y pesados trámites de un juicio ordinario". ${ }^{84}$

Las circunstancias geográficas de la "duplicidad de continentes" y "la falta de proporción y de equilibrio" entre España y sus posesiones trasatlánticas constituían otros elementos de facto que recomendaban la correspondiente separación de los órganos de poder, al imposibilitar la "unión moral" entre uno y otro hemisferio; y es que — argumentaba el cubano Joaquín Infante- "las instituciones para ser benéficas á un pais es preciso que emanen de aquellos á quienes interesan, y sean ellos mismos los ejecutores". 85

Si ese "monstruo político" ${ }^{86}$ llegó a durar trescientos años, en contra del propio curso de la naturaleza, esa larga pervivencia era atribuible a la fuerza de las armas, capaz de violentar las leyes naturales y de unir "bajo

83 Gaceta Patriótica del Ejército Nacional, 21-IV-1820, núm. 26 (LAF, 152).

84 J. M. C.: Reflexiones sobre la independencia. Parecido al punto de vista expresado en la Gaceta era el criterio del Pensador Mexicano, que también encontró la correspondiente réplica: "ies justa, ó no lo es, la independencia?: y por cuanto vd. ha tenido ya el atrevimiento de escribir, que es justa, pero que debe esperarse á que la determinen las Córtes; responda: ¿que se deberá hacer en caso de que las Córtes ó la denieguen, ó no quieran determinarla?" (Iturbide, Agustín de: Carta de D. Agustin de Iturbide al Pensador Mexicano. México, impresa en la oficina de D. José María Betancóurt, calle de San José el Real, núm. 2. Año de 1821. LAF, 207).

85 Infante: Solución á la cuestión de derecho sobre la emancipación de la America.

86 Así argumentaba Manuel de la Bárcena (Manifiesto al mundo), a propósito del carácter "antinatural" de la dominación española en América: "una monarquía existente en las cuatro partes del mundo; una monarquía constitucional, compuesta de España, Canarias, las Américas, y las Islas Filipinas como partes integrantes es mil veces mas dificil de realizar, que la república de Platon, es un despropósito, es un delirio, que solo puede tener lugar en la cabeza de algun político febricitante: y los que quieren sostener tan disforme edificio, me parecen tan locos como aquellos Jacobinos, que el año de mil setecientos noventa y tres querian establecer la república universal del género humano". 
un cetro pueblos tan distantes, y tan eterogéneos" ${ }^{87}$ Pero se trataba de una coacción éticamente injustificable, como también lo eran la anexión llevada a cabo por Cortés, contraria al derecho de gentes, y la donación de Alejandro VI, realizada sin atender a que los papas carecían de dominio temporal sobre los reyes.$^{88}$ En consecuencia, concluía al arcediano Manuel de la Bárcena, cuyo Manifiesto al mundo seguimos glosando, "no tubo pues la Peninsula, título legítimo para la adquisición de estos países; ni tampoco le tiene para retenerlos". ${ }^{89}$

87 Ibídem. En el Desafio literario sobre la independencia de la America Septentrional de la antigua España, de Juan Nazario Peimbert, se insistía en la oposición que el imperio español encontraba en la misma naturaleza: segun las circunstancias locales de la tierra; si la naturaleza nos há dividido más de mil y quinientas leguas, nuestra America puede considerarse en su govierno como un mostruo sin cabeza ¿Como podrá ser un Rey padre de sus pueblos, si se hallan tan distantes de su tutela?”. 88 Bárcena, M.: Manifiesto al mundo; J. M. C.: Reflexiones sobre la independencia, y Justicia de la independencia, ó apuntamientos sobre los derechos de los americanos.

89 Bárcena, M.: Manifiesto al mundo. 